ISAHP Article: Marrero-Oviedo, Diaz-Curbelo, Coello-Mena/ Macroergonomics Evaluation of a Logistic Procurement Process in a Production Plant of Kitchen Items. Paper Proposals To Be Submitted to the International Symposium of the Analytic Hierarchy Process 2014, Washington D.C., U.S.A.

\title{
MACROERGONOMICS EVALUATION OF A LOGISTIC PROCUREMENT PROCESS IN A PRODUCTION PLANT OF KITCHEN ITEMS
}

\author{
Michaerlys Marreo-Oviedo \\ Universidad Central "Marta Abreu" de Las Villas \\ Santa Clara, Villa Clara, Cuba \\ E-mail: michaerlys@uclv.edu.cu \\ Alina Díaz-Curbelo \\ Universidad Central "Marta Abreu" de Las Villas \\ Santa Clara, Villa Clara, Cuba \\ E-mail: alinadc@uclv.edu.cu \\ Jorge Coello-Mena \\ Constele Inc \\ Miami, FL, USA \\ E-mail: jorge@constele.com
}

\begin{abstract}
The procurement processes have as a principal function the material productions assurance. The evaluation and continuous improvement play a role in the efficiency, efficacy and effectiveness scope in the organization. The main aim was to construct an index that allows the integration of logistics management metrics, and ergonomic assessment in a procurement process on cookware manufacturing by using the ANP (Analytical Network Process) methodology. Several techniques and tools were used in retrieving the necessary information as: official documents review, the use of checklists, the Delphi methodology, the use of surveys, workgroup techniques and consultation with an expert panel; furthermore through the application of the software SuperDecisions it is possible to determine the evaluation of the integrated index in the aforementioned plant. The macroergonomics index (IEMaE Spanish acronym) calculated allowed us to determine the range in which improvements can be implemented and prioritized according to the weight they represent in the calculated index.
\end{abstract}

Keywords: macroergonomics, supply chains, logistics, procurement, indices.

\section{Introduction}

The measurement of the performance in a supply chain or logistic system could be identified as a powerful tool for the diagnosis to determine the gaps in the optimum performance of a supply chain or logistic process in particular. The identification of opportunities for improvement and in which areas these should be carried out could be summarised as "Performance management".

The measurement of performance in organizations is becoming an element of competitiveness and differentiation between among companies (Alfaro et. al., 2002). For this reason, in order to evaluate the performance of a beer supply chain and the distribution process in particular, it is a fundamental task to obtain the information that would allow competitive advantage. The identification of performance measures needed and their values which provide accurate information constitute a challenge for specialists and academics in this field. 
ISAHP Article: Marrero-Oviedo, Diaz-Curbelo, Coello-Mena/ Macroergonomics Evaluation of a Logistic Procurement Process in a Production Plant of Kitchen Items: ANP Aplication. Paper Proposals To Be Submitted to the International Symposium of the Analytic Hierarchy Process 2014, Washington D.C., U.S.A.

The objective of this article is to evaluate the beer distribution process taking into account a practical case study. For this purpose, an index is searched that would integrate the different metrics and criteria of the logistic management with the tools of macroergonomics evaluation. The index is formed taking the performance of the logistic process under study as a base and the conditions in which the users interact, i.e. the human resources.

\section{Literature Review}

Although many authors have established various key performance indicators demonstrating its usefulness in the context of the supply chain, there are few studies which focus Performance Management from a global, integrated perspective in this area. The simplified model proposed by Chan et. al. (2003) guarantees the performance measure to provide the necessary assistance to the improved management of the supply chain. For each process and their associated sub - processes that need to be measured, appropriate measures are identified and grouped in a hierarchical manner. This method allows the evaluation of processes and threads as shown in Figure 1.

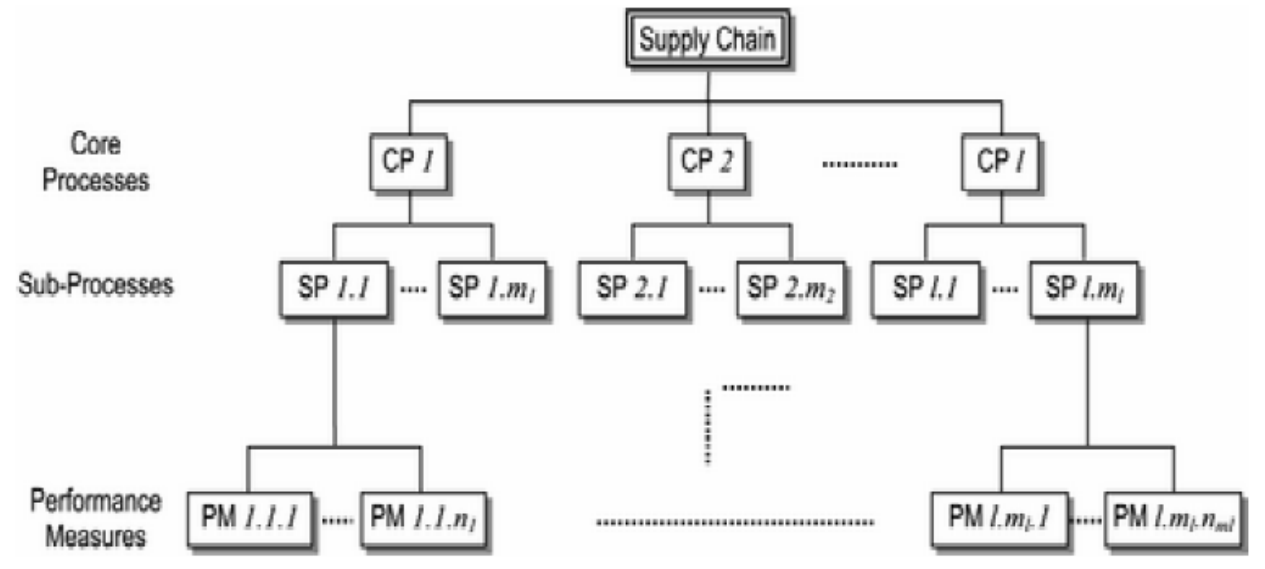

Figure 1: General structure of the processes and measures hierarchy.

Hendrick and Kleiner (2001) formalize a method of intervention work systems based on the theory of socio-technical systems, denominated "MEAD" for its acronym in English to improve macroergonomic structure analysis and design.

In this case the macroergonomics can be used as a support tool for improving work systems in the processes of the supply chain (Hartono, 2008), considering that each process must maintain comfortable working conditions, adequate material flow scenarios, safe working environment, teamwork and other ergonomic variables that can directly influence the efficiency of the work developed in a supply chain process.

Extrapolating this experience from the macroergonomics and integration points of view will provide better approximation to the magnitude of the problems affecting work systems associated with logistics processes.

This would provide quantitative analysis for the design of intervention programs in work systems. We attempt to provide an answer to this necessity in this investigation. 
ISAHP Article: Marrero-Oviedo, Diaz-Curbelo, Coello-Mena/ Macroergonomics Evaluation of a Logistic Procurement Process in a Production Plant of Kitchen Items: ANP Aplication. Paper Proposals To Be Submitted to the International Symposium of the Analytic Hierarchy Process 2014, Washington D.C., U.S.A.

\section{Hypotheses/Objectives}

This research aims to determine an evaluation index of organizational performance using the ANP methodology. This methodology will integrate organizational performance metrics identified in management and logistics processes to the context of the man working conditions. The calculation of the index will be made using the software SuperDecisions, facilitating the calculation of the weights and priorities in the model created.

\section{Research Design/Methodology}

To achieve the objective of this research and based on the analysis of the literature carried out in the previous section, a procedure is proposed, which will provide the macroergonomics evaluation of the distribution processes (see Figure 2).

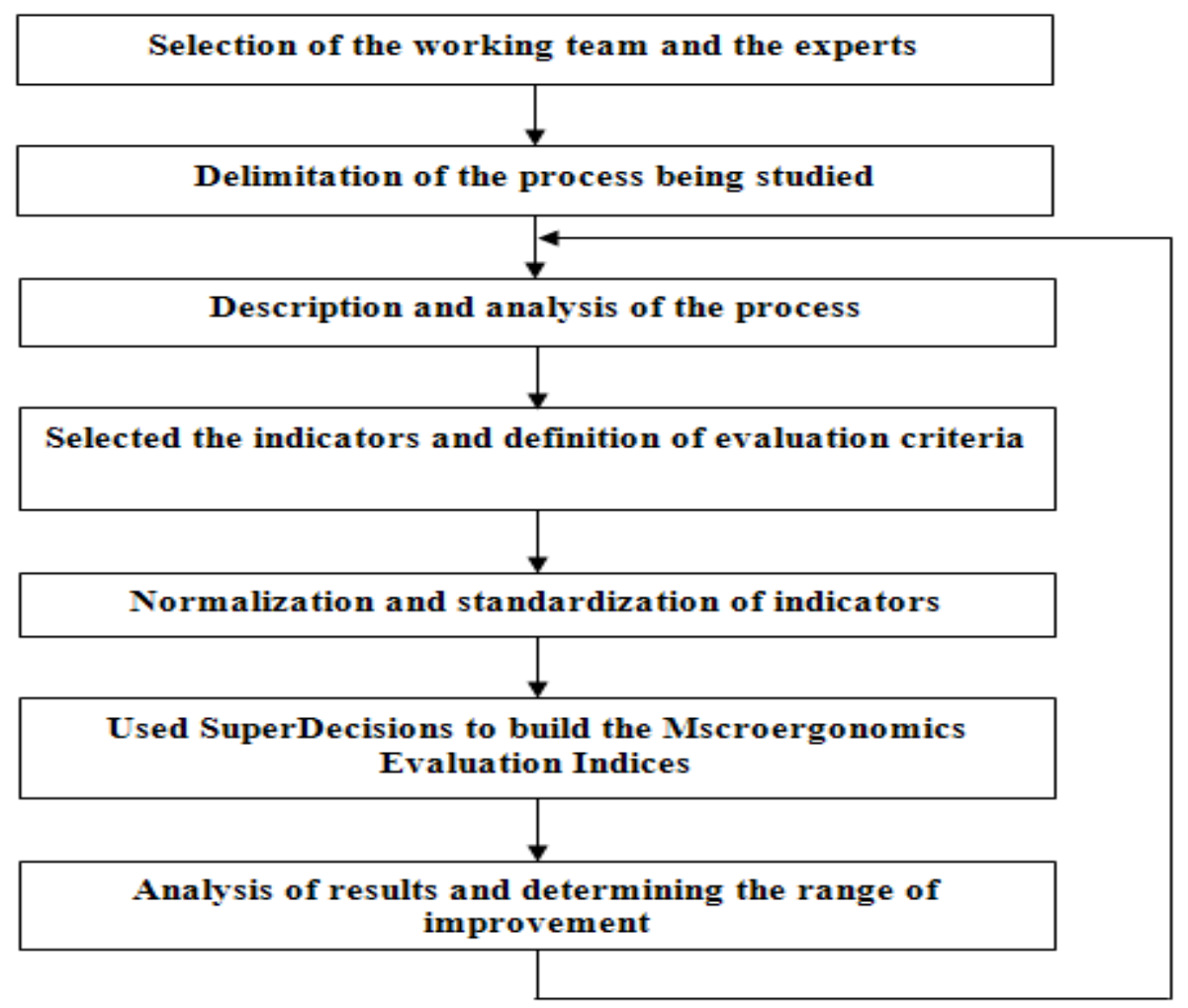

Figure 2: Procedure for macroergonomics assessment of procurement processes

\section{Data/Model Analysis}

The selected indicators are grouped into four assessment criteria, which vary depending on the process being evaluated. For the process under study these criteria are grouped into: (1) working conditions, (2) efficiency indicators, (3) procurement management indicators, and (4) psychosocial aspects of work. The determination of the weights is performed using the SuperDecisions software whose use will be described in the following sequence: 
ISAHP Article: Marrero-Oviedo, Diaz-Curbelo, Coello-Mena/ Macroergonomics Evaluation of a Logistic Procurement Process in a Production Plant of Kitchen Items: ANP Aplication. Paper Proposals To Be Submitted to the International Symposium of the Analytic Hierarchy Process 2014, Washington D.C., U.S.A.

1. The structural model of the index shown in Figure 3.

2. The matrix of global and local scope produced evidence of relationships between the groups and different nodes that make up the model.

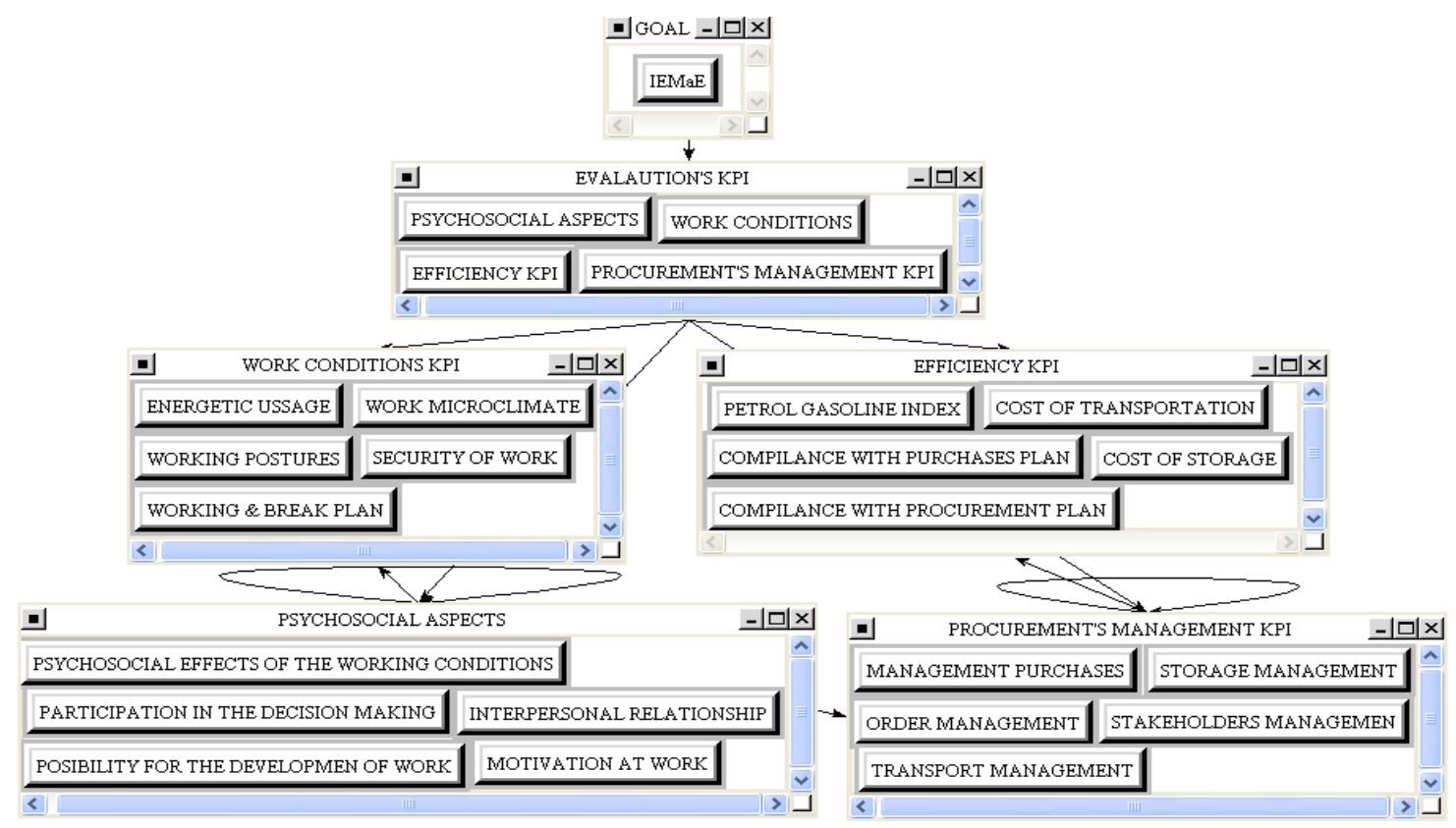

Figure 3: The structural model of the IEMaE

3. Choices casted to determine the importance of the elements are shown in Figure 4. In all cases the calculated inconsistency does not exceed $10 \%$.

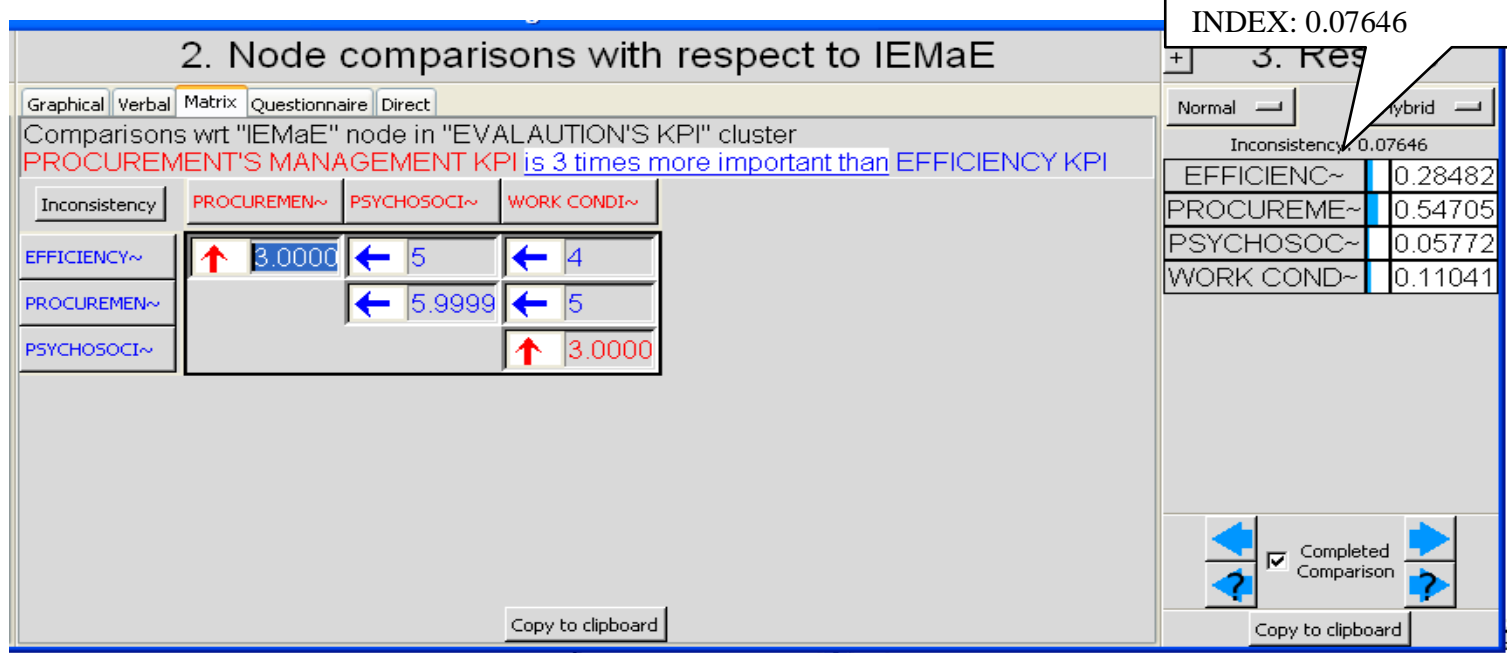

Figure 4: Relative importance between the evaluated elements. 
ISAHP Article: Marrero-Oviedo, Diaz-Curbelo, Coello-Mena/ Macroergonomics Evaluation of a Logistic Procurement Process in a Production Plant of Kitchen Items: ANP Aplication. Paper Proposals To Be Submitted to the International Symposium of the Analytic Hierarchy Process 2014, Washington D.C., U.S.A.

Using a rating scale provides a comparative measure of the performance obtained in the performance evaluation of the procurement process studied. The scale would show the values in which it is considered in a qualitative manner the work system performance.

\section{Limitations}

The main limitation of the research is the lack results in correlation and sensitivity analysis among the existing indicators listed in the developed model. These studies are intended to be carried out in the development of further research.

\section{Conclusions}

The applied procedure generates the index of macroergonomics evaluation for a procurement process, evaluating in an integrated way the elements and metrics from both, logistic and macroergonomics nature.

The ANP methodology used in shaping the decision model fosters an integral dimension into the indicators of organizational performance. This feature will allow the application of this toolset in the work systems.

\section{Key References}

Alfaro, J. J., Ortiz, A., Poler, R. (2002). Definición de parámetros de prestaciones bajo un enfoque de integración empresarial. II Conferencia de Ingeniería de Organización, Vol. I, pp. 269-276.

Chan, T.S.; Qi, H.J. (2003). Feasibility of performance measurement system for supply chain: a process-based approach and measures. Integrated Manufacturing Systems, Vol. 14, No 3, pp. 179-190.

Hartono, M. (2008). Incorporating Ergonomics into Supply Chain Systems. Journal of Logistics and Supply Chain Management, Vol. 1, No. 2. pp. 61-71.

Hendrick H.W.; Kleiner B.M. (2001). Macroergonomics: An introduction to work system design. Human Factors and Ergonomics Society, Santa Monica, CA Hendrick and Kleiner (2001). 